\title{
A EFETIVAÇÃO DO DIREITO À INFORMAÇÃO AMBIENTAL, POR MEIO DA QUESTÃO PREJUDICIAL, NO TRIBUNAL DE JUSTIÇA DA UNIÃO EUROPEIA
}

\author{
THE IMPLEMENTATION OF THE RIGHT TO ENVIRONMENTAL INFORMATION \\ THROUGH PRELIMINARY RULING ON EUROPEAN COURT OF JUSTICE
}

Luciane Klein Vieira $^{1}$

Victória Maria Frainer ${ }^{2}$

\begin{abstract}
Resumo: O presente artigo analisa a efetivação do direito à informação ambiental, na União Europeia (UE), por meio da atuação do Tribunal de Justiça da União Europeia (TJ/UE), em sede de questão prejudicial, mecanismo que permite um diálogo horizontal entre o juiz comunitário e o juiz nacional. A temática se justifica diante da relevância da informação ambiental para a vida em sociedade, a fim de se alcançar a meta da Organização das Nações Unidas vinculada ao consumo sustentável. Assim, o problema de pesquisa que guiou esse estudo analisa se a questão prejudicial é o mecanismo apto para se alcançar a uniformização da interpretação e posterior aplicação, pelo juiz nacional, do direito à informação ambiental, erigido pelas instituições da UE diante da disparidade ainda presente na legislação de cada Estado Membro. Entre os objetivos buscados estão: analisar a cooperação jurídica entre o TJ/UE e os tribunais nacionais, na esfera da questão prejudicial; identificar os principais casos decididos pelo TJ/UE, entre 1992 e junho de 2019, relativos ao direito à informação ambiental; e, por fim, estudar a fonte originária e derivada do Direito da União, com foco na informação ambiental. Para tanto, utilizou-se o método de análise normativo-descritivo de cunho documental, sob uma perspectiva crítica e interdisciplinar, enquanto o método utilizado para o levantamento de casos foi o empírico por amostragem. Desse modo, fez-se possível concluir que a questão prejudicial é essencial na efetivação do direito à informação ambiental nos moldes adotados pela UE, a fim de gerar mudanças dos hábitos dos consumidores.
\end{abstract}

Palavras-chave: Informação ambiental; Consumo sustentável; União Europeia; Questão prejudicial.

Abstract: This article analyzes the achievement of the right to environmental information within the European Union, through the preliminary ruling of the European Union Court of Justice, mechanism that allows a horizontal dialogue between the judge Community and the national judge. The theme is justified in view of the relevance of environmental information for life in society, in order to achieve the United Nations goal linked to sustainable consumption. The aim of this study is to verify whether the question referred for a preliminary ruling is the appropriate mechanism to standardize interpretation and subsequent application by the national court of the right to environmental information erected by the EU institutions in the face of disparity still present in the legislation of each Member State. Specific objectives include: analyzing legal cooperation between the European Court of Justice and the national courts, regarding the question referred for a preliminary ruling; identify the main cases decided by the Court of Justice between 1992 and June 2019 on the right to environmental information and the question referred for a preliminary ruling; and, finally, to study the source originated and derived from the Law of the Union, with emphasis in the environmental information. In order to do so, the methodology of normative-descriptive analysis was used, from a critical and interdisciplinary perspective and for the survey of cases, the method used was empirical by sampling.

1 Professora do Programa de Pós-Graduação em Direito da Universidade do Vale do Rio dos Sinos (UNISINOS). Doutora em Direito (área: internacional) pela Universidad de Buenos Aires - UBA. E-mail: lucianekleinvieira@yahoo.com.br

2 Bacharel em Direito pela Universidade do Vale do Rio dos Sinos. Ex-bolsista de Iniciação Científica da UNISINOS. E-mail: victoria_frainer@hotmail.com 
Thereby, it was possible to conclude that the mechanism of the preliminary question is essential for the realization of the right to environmental information along the lines adopted by the EU in order to generate changes in consumer habits.

Keywords: Environmental information; Sustainable consumption; European Union; Preliminary rulings.

\section{INTRODUÇÃO}

O direito à informação, no aspecto ambiental, representa um mecanismo de poder por permitir que a população, especialmente o consumidor, participe de decisões que afetam o meio ambiente e, por via de consequência, a vida e a saúde humana. Além disso, com acesso à informação, as pessoas estarão aptas a realizar escolhas mais conscientes ao consumir, privilegiando, por exemplo, produtos com "etiqueta verde" que respeitam os critérios de sustentabilidade em sua produção e elaboração, em detrimento daqueles que não o fazem. Logo, é de suma importância o acesso à informação simplificada, completa, de qualidade e amplamente disponível, repercutindo em inclusão e maior consciência ambiental.

Quanto ao meio ambiente, considerando sua característica transnacional, a atuação dos países em blocos regionais, como a União Europeia, garante a efetivação ampla e integrada das normas que promovem o desenvolvimento sustentável, objetivo para 2030 da Organização das Nações Unidas (ONU). Tal meta, foi oficializada em 2015 com a aprovação da "Agenda 2030 para o Desenvolvimento Sustentável" pela Assembleia Geral da ONU, ${ }^{3}$ sendo oportuno citar seu preâmbulo, em que a necessidade da proteção do planeta é ressaltada nos seguintes termos:

Estamos determinados a proteger o planeta da degradação, sobretudo por meio do consumo e da produção sustentáveis, da gestão sustentável dos seus recursos naturais e tomando medidas urgentes sobre a mudança climática, para que ele possa suportar as necessidades das gerações presentes e futuras. (ONU: 2015).

3 A internalização da Agenda 2030 ocorreu por meio de diversos documentos próprios do Direito da União, tais como: Resolução do Parlamento Europeu, de 12 de maio de 2016, sobre o acompanhamento e a revisão da Agenda 2030. (PARLAMENTO EUROPEU: 2016); Regulamento (UE) 2017/1601 do Parlamento Europeu e do Conselho da União Europeia, de 26 de setembro de 2017, que institui o Fundo Europeu para o Desenvolvimento Sustentável (FEDS), a Garantia FEDS e o Fundo de Garantia FEDS. (PARLAMENTO EUROPEU: 2017); Decisão (UE) 2018/881 do Conselho da União Europeia, de 18 de junho de 2018, que contém um pedido à Comissão no sentido de apresentar um estudo sobre as opções da União para responder às conclusões do Comité de Avaliação do Cumprimento da Convenção de Aarhus no processo ACCC/C/2008/32 e, se adequado à luz do resultado do estudo, para apresentar uma proposta de regulamento do Parlamento Europeu e do Conselho que altere o Regulamento (CE) n 1367/2006. (CONSELHO DA UNIÃO EUROPEIA: 2018); Regulamento (UE) 2019/2088 do Parlamento Europeu e do Conselho da União Europeia, de 27 de novembro de 2019, relativo à divulgação de informações relacionados com a sustentabilidade no setor dos serviços financeiros. (PARLAMENTO EUROPEU: 2019); Comunicação da Comissão ao Parlamento Europeu, ao Conselho, ao Comitê Econômico e Social Europeu e ao Comitê das Regiões: uma parceria global para a erradicação da pobreza e o desenvolvimento sustentável pós-2015. (COMISSÃO EUROPEIA: 2015); e, Documento de Reflexão para uma Europa sustentável até 2030. (COMISSÃO EUROPEIA: 2019). 
Cabe destacar que, não obstante a adesão da União Europeia à Agenda 2030, o Relatório sobre o Desenvolvimento Sustentável na Europa (SDSN e IEEP: 2019; p. 9) apontou a necessidade de os Estados Membros acelerarem o processo de aplicação do ODS 12, ${ }^{4}$ vez que apresentaram a pontuação mais baixa em relação aos outros ODS. ${ }^{5}$

$\mathrm{Na}$ União Europeia, o direito à informação ambiental é aplicado de forma contínua pelos Estados Membros, desde a Diretiva 90/313/CEE e, hoje, com a Diretiva 2003/4/CE combinada ao Regulamento $\mathrm{n}^{\mathrm{0}}$ 1367/2006, ambos em conformidade com a Convenção sobre Acesso à Informação, Participação do Público no Processo de Tomada de Decisão e Acesso à Justiça em Matéria de Ambiente, também designada como Convenção de Aarhus (COMISSÃO ECONÔMICA DAS NAÇÕES UNIDAS PARAA EUROPA: 1998). ${ }^{6}$ A referida Convenção procura consolidar o princípio da informação ambiental no âmbito internacional, colocando em prática os enunciados do artigo 191 do TFUE e do Princípio 10 da Declaração do Rio sobre Meio Ambiente e Desenvolvimento. ${ }^{7}$

No entanto, diante da idiossincrasia de cada Estado Membro e, ante a necessidade de aplicação uniforme do Direito da União Europeia em todo o território integrado, tornou-se imperativa a utilização de ferramentas para efetivar os direitos previstos, motivo pelo qual o mecanismo denominado questão prejudicial, cuja competência é exclusiva do Tribunal de Justiça da União Europeia (TJ/UE), poderia ser o principal instrumento apontado para dar coesão e estabilidade ao direito produzido pelo bloco.

Nesse sentido, o presente estudo busca responder à seguinte questão: a ferramenta questão prejudicial está apta para uniformizar a interpretação e aplicação do direito à informação ambiental na União Europeia diante da disparidade ainda apresentada nas legislações de cada Estado Membro, na matéria? Apresenta-se como hipótese de trabalho que a questão prejudicial é essencial para a consecução da aplicação uniforme do direito à informação ambiental, produzido pela União Europeia. Ademais, possibilita também a cooperação jurídica direta entre o juiz nacional e o Tribunal de Justiça do bloco, tornando possível a efetivação do acesso à informação ambiental de forma clara, completa e célere em todos os Estados Membros.

4 "Garantir padrões de consumo e de produção sustentáveis.". (ONU: 2015).

5 Em observância ao Relatório produzido, a Comissão Europeia publicou, em 30 de janeiro de 2019, o "Documento de Reflexão: para uma Europa sustentável até 2030", no qual reforçou a relação entre a sobrevivência humana com a melhora nos padrões de produção e consumo. (COMISSÃO EUROPEIA: 2019; p. 8).

6 Não obstante a assinatura da Convenção de Aarhus, em 1998, pela Comunidade Europeia e seus Estados Membros, sua aprovação definitiva ocorreu por meio da Decisão 2005/370/CE do Conselho da União Europeia, de 17 de fevereiro de 2005, relativa à celebração, em nome da Comunidade Europeia, da Convenção sobre o acesso à informação, participação do público no processo de tomada de decisão e acesso à justiça em matéria de ambiente. (CONSELHO DA UNIÃO EUROPEIA: 2005).

7 Princípio 10: "O melhor modo de tratar as questões ambientais é com a participação de todos os cidadãos interessados, em vários níveis. No plano nacional, toda pessoa deverá ter acesso adequado à informação sobre o ambiente de que dispõem as autoridades públicas, incluída a informação sobre os materiais e as atividades que oferecem perigo a suas comunidades, assim como a oportunidade de participar dos processos de adoção de decisões. Os Estados deverão facilitar e fomentar a sensibilização e a participação do público, colocando a informação à disposição de todos. Deverá ser proporcionado acesso efetivo aos procedimentos judiciais e administrativos, entre os quais o ressarcimento de danos e recursos pertinentes.". (UNITED NATIONS: 1993; p. 10). 
Além disso, o artigo apresenta como objetivo principal verificar se a questão prejudicial é o mecanismo apto para a uniformização da interpretação e posterior aplicação, pelo juiz nacional, do direito à informação ambiental. Igualmente, atende aos seguintes objetivos específicos: analisar como ocorre a cooperação jurídica entre o TJ/UE e os tribunais nacionais de seus Estados Membros, no âmbito da questão prejudicial; identificar os principais casos decididos pelo TJ/UE, no âmbito do tema pesquisado, no período de 1992 até junho de 2019; e, estudar a fonte originária e derivada do Direito da União, em especial o direito à informação ambiental.

Para tanto, utiliza-se o método de análise normativo-descritivo, de cunho documental, sob uma perspectiva crítica e interdisciplinar, considerando para tanto o estudo do Direito da União Europeia, sobretudo em matéria de cooperação jurídica internacional e direito ambiental. Já para a coleta dos principais casos referentes ao direito à informação ambiental, decididos pelo TJ/UE, foi utilizada a pesquisa empírica por amostragem.

A partir da metodologia de trabalho exposta, o presente artigo está estruturado em duas partes: a primeira, procura apresentar o Direito da União e o TJ/UE, para, a partir disso, estudar o funcionamento da questão prejudicial e a sua contribuição para a sedimentação dos principais postulados do Direito do bloco; a segunda, mais específica, procura analisar o direito europeu à informação ambiental, tanto em matéria convencional, quanto com relação ao direito de fonte autônoma, produzido pelas instituições europeias, para logo, verificar como a partir da atuação do Tribunal referido, pode auxiliar na consolidação do acesso à informação ambiental como ferramenta para a uniformização da interpretação e aplicação do Direito da União e para a consecução do objetivo do consumo sustentável.

\section{A UNIÃO EUROPEIA}

A União Europeia, na forma conhecida atualmente, é o resultado de um longo processo de evolução. De início, com intuito de evitar novas guerras entre os países vizinhos - sobretudo envolvendo a Alemanha vencida, devastada no Pós-Guerra - e, por via de consequência, garantir a paz, buscou-se a união dos países europeus sob o viés econômico, tendo sido assinado, para tanto, o Tratado de Paris, em 18 abril de 1951, por seus seis Estados fundadores (Alemanha, Bélgica, França, Itália, Luxemburgo e Países Baixos), ocasião em que se instituiu a Comunidade Europeia de Carvão e do Aço (CECA). Após, em 25 de março de 1957, com a assinatura dos Tratados de Roma, foram instituídas a Comunidade Econômica Europeia (CEE) - para a consecução do "Mercado Comum" - e a Comunidade Europeia da Energia Atômica (EURATOM), tendo os referidos Tratados entrado em vigor no dia 01 de janeiro de 1958. Oportuno salientar a ausência de disposições referentes à proteção ambiental nos Tratados constitutivos das Comunidades Europeias, demonstrando, de início, a falta de prioridade do meio ambiente e sua proteção no processo de integração europeu.

Posteriormente, em 1987, com a vigência do Ato Único Europeu (responsável por revisar o Tratado de Roma), os Estados Membros desenvolveram um projeto para, no prazo de seis anos, eliminar entraves às liberdades de circulação (mercadorias, serviços, fatores de produção e capitais estrangeiros), essenciais para a efetivação do "Mercado Único", o que foi concretizado somente em 
1992, com o Tratado de Maastricht, que entrou em vigor em 01 de novembro de 1993. O Tratado mencionado foi responsável pela criação da União Europeia propriamente dita, refundada na supranacionalidade, característica gerada pela cessão parcial da soberania estatal. (VIEIRA; ARRUDA: 2018; p. 288). Nesta oportunidade, pela primeira vez a proteção do meio ambiente foi citada como um dos objetivos principais do bloco, demonstrando, de vez, a necessidade de adoção de uma política comum ambiental. Desta forma, programas ambientais e regulamentos que abordavam a matéria ambiental passaram a ter fundamento comunitário. (BASSO: 1995; p. 193-233).

Oportuno ressaltar que, embora o Tratado de Maastricht (1992) seja denominado como Tratado da União Europeia, este não realizou a extinção da CEE, mas sim a modificou, vez que os objetivos econômicos, bem como o grau de compromisso dos Estados Membros foram ampliados com a adoção de uma estrutura institucional conhecida como os Pilares da União Europeia. (VIEIRA: 2013a; p. 91-142). Logo após Maastricht, houve a integralização da política ambiental nas demais políticas do bloco, instituindo como missão a proteção e melhoria da qualidade do meio ambiente, o que foi feito com o Tratado de Amsterdã (1999).

Por fim, o Tratado de Nice (2003) inseriu alterações significativas no Tratado da União Europeia, determinando, além da missão referida, em seu art. $2^{\circ}$, que o desenvolvimento harmonioso, equilibrado e sustentável é um dos principais objetivos do bloco.

Nos anos seguintes, considerando a ampliação da organização internacional em análise, os atos constitutivos que a regiam até então mostraram-se insuficientes para alcançar os objetivos propostos, tornando-se necessário rever o funcionamento do bloco. Para tanto, houve a construção do denominado Tratado Reformador, posteriormente chamado como Tratado de Lisboa, que modificou dois importantes tratados constitutivos, que são: o Tratado de Maastricht (1992) e o Tratado de Roma (1957), substituindo-os pelo Tratado da União Europeia (TUE) e Tratado de Funcionamento da União Europeia (TFUE).

Portanto, foi com o Tratado de Lisboa, assinado em 13 de dezembro de 2007 pelos 27 Estados Membros da época - posteriormente ratificado por cada um deles - que a União Europeia tomou a forma atual, prevendo, no seu artigo 26, item 2, do TFUE (2007), as quatro principais liberdades de circulação, já mencionadas, além dos objetivos econômicos de maior profundidade, que encaminharam a União Europeia à busca da consolidação da união econômica monetária. ${ }^{8}$ Ainda, procedeu a reformas importantes, tais como indicar a luta contra as alterações climáticas como um objetivo comum do bloco, de forma explícita, além de tornar a Carta dos Direitos Fundamentais da União Europeia (CDFUE) instrumento jurídico vinculante. Em relação à CDFUE (2000), o art. $37^{9}$ expressamente indica que todas as políticas da União Europeia deverão visar a proteção do meio

8 Conforme a doutrina, o processo de integração econômica desenvolve-se em cinco etapas principais: área de preferências tarifárias, zona de livre comércio, união aduaneira, mercado comum e união econômica, sendo a última o modelo de integração no qual a União Europeia encontra-se hoje, que ocorre quando os países integrantes de um mercado comum, ou seja, que já aplicam as "quatro liberdades de circulação" (de bens, serviços, pessoas e capitais), acordam em unificar a política econômica, podendo adotar, ou não, uma moeda única. (ZALDUENDO: 2013; p. 3-24).

9 Art. 37: "Todas as políticas da União devem integrar um elevado nível de proteção do ambiente e a melhoria da sua qualidade, e assegurá-los de acordo com o princípio do desenvolvimento sustentável.". (CDFUE: 2000). 
ambiente, em respeito ao princípio do desenvolvimento sustentável. Ainda, o mesmo diploma indica, no art. 11, item 1, a liberdade de expressão e informação, o que abarca, inclusive, o direito de receber informações, independente das fronteiras.

No contexto atual, a União Europeia está constituída por 27 Estados Membros ${ }^{10}$ e conta, ainda, com cinco Estados candidatos, ${ }^{11}$ que estão em fase de transposição da legislação europeia ao direito nacional, um dos requisitos para a futura admissão. Em linhas gerais, nos termos do artigo 49 do TUE (2007), ${ }^{12}$ qualquer país europeu pode candidatar-se à adesão ao bloco, cujo pedido fica condicionado à decisão final, por unanimidade do Conselho Europeu, acompanhada de recomendação do Parlamento Europeu, bem como da aprovação interna dos Estados. Embora qualquer país europeu possa candidatar-se à condição de aderente, deverá observar os chamados Critérios de Copenhague (CONSELHO EUROPEU DE COPENHAGA: 1993), atualizados em 1995 no Conselho Europeu de Madrid, a fim de viabilizar a sua candidatura seguindo critérios políticos, econômicos e capacidade para assumir suas obrigações, inclusive o cumprimento de metas da união política, econômica e monetária.

Contudo, cabe referir que o Reino Unido - membro do bloco europeu desde 1973 - realizou em 23 de junho de 2016 um referendo sobre a permanência ou não na União Europeia, cujo resultado foi favorável à sua saída. O procedimento para saída do bloco encontra-se previsto no artigo 50 do TUE (2007) e foi perfectibilizado com a celebração do "Acordo de Saída" (CONSELHO DA UNIÃO EUROPEIA: 2019), que entrou em vigor no dia 31 de janeiro de 2020, iniciando o período de transição que se estende até 31 de dezembro de $2020 .^{13}$

10 Os Estados Membros atuais da União Europeia são: Alemanha, Áustria, Bélgica, Bulgária, Chipre, Croácia, Dinamarca, Eslováquia, Eslovênia, Espanha, Estônia, Finlândia, França, Grécia, Hungria, Irlanda, Itália, Letônia, Lituânia, Luxemburgo, Malta, Países Baixos, Polônia, Portugal, República Checa, Romênia e Suécia. Oportuno destacar que a Croácia foi o último membro a ingressar, em 01 de julho de 2013.

11 Atualmente, há cinco países candidatos ao ingresso na União Europeia, os quais estão em fase de transposição da legislação europeia para o direito nacional, são eles: Albânia, Antiga República Iugoslava da Macedônia, Montenegro, Sérvia e Turquia.

12 Art. 49: "Qualquer Estado europeu que respeite os valores referidos no artigo 2. ${ }^{\circ}$ e esteja empenhado em promovê-los pode pedir para se tornar membro da União. O Parlamento Europeu e os Parlamentos nacionais são informados desse pedido. O Estado requerente dirige o seu pedido ao Conselho, que se pronuncia por unanimidade, após ter consultado a Comissão e após aprovação do Parlamento Europeu, que se pronunciará por maioria dos membros que o compõem. São tidos em conta os critérios de elegibilidade aprovados pelo Conselho Europeu. As condições de admissão e as adaptações dos Tratados em que se funda a União, decorrentes dessa admissão, serão objeto de acordo entre os Estados-Membros e o Estado peticionário. Esse acordo será submetido à ratificação de todos os Estados Contratantes, de acordo com as respectivas normas constitucionais.". (TUE: 2007).

13 Para mais informações ver o Comunidade de Imprensa emitido pelo Conselho da União Europeia, no dia 30 de janeiro de 2020. (CONSELHO DA UNIÃO EUROPEIA: 2020). 


\subsection{O DIREITO DA UNIÃO E O TRIBUNAL DE JUSTIÇA DA UNIÃO EURO- PEIA}

A integração da Europa repercutiu na necessidade da criação de uma nova ordem jurídica, autônoma e distinta dos ordenamentos jurídicos nacionais, destinada a regular não somente o funcionamento da União Europeia, como também a vida dos cidadãos, a fim de garantir um futuro próspero à Europa integrada. De forma que, os Estados Membros movidos por interesses comuns e baseados na cessão da supranacionalidade (MACHADO: 2013; p. 86-90) criaram o denominado Direito da União.

Sobre a interação do Direito da União e o direito nacional é possível afirmar que as ordens jurídicas são independentes, mas cooperam entre si, como dispõe o art. $4^{\circ}$, item 3 , do Tratado de Lisboa (2007), in verbis:

Em virtude do princípio da cooperação leal, a União e os Estados-Membros respeitamse e assistem-se mutuamente no cumprimento das missões decorrentes dos Tratados. Os Estados-Membros tomam todas as medidas gerais ou específicas adequadas para garantir a execução das obrigações decorrentes dos Tratados ou resultantes dos atos das instituições da União. Os Estados-Membros facilitam à União o cumprimento da sua missão e abstêmse de qualquer medida susceptível de pôr em perigo a realização dos objetivos da União. (UNIÃO EUROPEIA, 2007).

Portanto, pode-se dizer que não há uma hierarquia vertical entre o TJ/UE e os tribunais nacionais, mas sim um modelo de cooperação horizontal, sendo que, enquanto o Tribunal comunitário interpreta o Direito da União para garantir a aplicação uniforme deste, os juízes nacionais efetivamente aplicam o Direito, vez que, conforme será visto em momento oportuno, a atuação do TJ/UE, via questão prejudicial, não envolve a resolução do caso concreto.

Sob a ótica do direito ambiental, para Alexandra Aragão:

O Direito Europeu do Ambiente é um conjunto de normas jurídicas, composto pelas disposições específicas do Tratado sobre o Funcionamento da União Europeia (especialmente os artigos $191^{\circ}$ a $193^{\circ}$, núcleo duro da política ambiental, mas também pelo artigo $11^{\circ}$, relativo à integração do ambiente nas restantes políticas) e por uma extensa constelação de actos jurídicos de direito secundário do ambiente, de onde destacamos o dever europeu de sancionar penalmente as infracções ambientais graves cometidas em território dos Estados. (ARAGÃO: 2009; p. 48).

Reforçando a ideia de atuação conjunta entre a União Europeia e os Estados Membros, há o dispositivo $4^{\text {o }}$, item 2 , do TFUE (2007) ${ }^{14}$ que prevê expressamente o meio ambiente como matéria de competência compartilhada, assim como a defesa dos consumidores, o que inclui o direito à

14 Artigo 4: "2. As competências partilhadas entre a União e os Estados-Membros aplicam-se aos principais domínios a seguir enunciados: a) Mercado interno; b) Política social, no que se refere aos aspectos definidos no presente Tratado; c) Coesão económica, social e territorial; d) Agricultura e pescas, com exceção da conservação dos recursos biológicos do mar; e) Ambiente; f) Defesa dos consumidores; g) Transportes; h) Redes transeuropeias; i) Energia; j) Espaço de liberdade, segurança e justiça; k) Problemas comuns de segurança em matéria de saúde pública, no que se refere aos aspectos definidos no presente Tratado.”. (TFUE: 2007). 
informação ambiental relacionado à liberdade de escolha do consumidor com relação ao produto a ser consumido.

Não obstante o exposto, é imperativo advertir que entre as fontes jurídicas do Direito da União, no que tange ao direito primário ou originário, ${ }^{15}$ restam abarcados todos os tratados constitutivos da União Europeia, com os respectivos aditamentos e alterações, bem como a Carta dos Direitos Fundamentais e os princípios próprios do Direito do bloco.

Lado outro, encontram-se abrangidas na esfera do direito derivado ou secundário as disposições normativas criadas pelas instituições da União Europeia (sobretudo, Comissão, Conselho e Parlamento Europeu), a saber: regulamentos, diretivas, decisões, recomendações e, por fim, pareceres, todos previstos no art. $288^{\circ}$ do TFUE (2007). Contudo, nem todos os atos jurídicos do direito derivado possuem a mesma natureza e alcance jurídico. Assim, embora o presente artigo não tenha como finalidade exaurir o Direito da União, tendo em vista sua relação direta com os regulamentos, as diretivas e as decisões judiciais, faz-se necessário realizar breve explicação sobre estes atos.

Os regulamentos são atos unilaterais com duas características essenciais: o caráter comunitário e a aplicabilidade direta. Assim, o direito previsto em um regulamento é imposto aos Estados Membros, de forma integral, mesmo se for contrário aos interesses particulares de dado país; já a segunda característica dispensa a criação de normas especiais nacionais para transposição, vez que as organizações, autoridades e cidadãos estão diretamente vinculados ao regulamento a partir da data de entrada em vigência nele prevista e, na ausência desta, no vigésimo dia seguinte à publicação do ato no Jornal Oficial da União Europeia, tornando mais ágil a aplicação do Direito da União.

Por sua vez, as diretivas fornecem maior flexibilidade aos Estados Membros, porquanto elas os vinculam somente com relação ao resultado a ser alcançado, sem indicar os meios para tanto. Portanto, afirma-se que "a diretiva é o ato jurídico que exibe maior grau de originalidade entre as formas jurídicas do querer normativo". (MELO; AMARAL JÚNIOR: 2016; p. 537 apud DUARTE: 2012; 423-439). Diferente dos regulamentos, as diretivas não servem como instrumentos de uniformização do Direito da União, mas sim como meio de conciliar os objetivos supranacionais com as particularidades nacionais, motivo pelo qual há necessidade de transposição ao direito nacional das disposições das diretivas, o que acontece em duas fases: a primeira, ocorre no âmbito da União Europeia, que estabelece o objetivo a ser realizado e o prazo para tanto; a segunda, em nível nacional, cabendo ao Estado Membro escolher a forma de transposição, observando o prazo previsto na diretiva, geralmente de dois anos, contados da sua publicação. (VIEIRA: 2017; p. 433). Embora, em regra, não se admita a aplicabilidade direta nas diretivas, ou seja, sua aplicação sem o ato de transposição pelo Estado Membro, o TJ/UE, em sede de construção jurisprudencial, decidiu que cumpridos determinados requisitos há a possibilidade da aplicação direta das diretivas, ${ }^{16}$ sobretudo quando os Estados Membros não procederem a transposição no prazo determinado, o que se tem denominado como efeito horizontal das diretivas.

$15 \mathrm{O}$ direito primário pode também ser chamado de direito originário, vez que é desvinculado das normas anteriores, servindo de "parâmetro material e formal de controle do direito secundário". (MELO; AMARAL JÚNIOR: 2016; p. 536-563).

16 As condições para aplicação direta da diretiva restaram previstas no Acórdão do TJUE, de 22 de junho de 1989, processo n 103/88, caso "Fratelli Costanzo", Coletânea 1839, considerando 31. 
As decisões judiciais, por fim, são atos vinculativos obrigatórios em todos os seus elementos, nos termos do art. 288, item 4, do TFUE (2007), além disso, podem ser divididos em duas categorias: decisões que indicam os destinatários, com aplicabilidade individual e as gerais, igualmente vinculativas, no entanto, para determinar a quem se aplicam é necessária a análise do conteúdo das mesmas. (BORCHARDT: 2017; p. 110).

A integração europeia, aliada ao fortalecimento do Direito da União, mostrou-se possível com o desempenho de um órgão jurisdicional supranacional, o TJ/UE, cuja criação ocorreu ainda em 1952 com o Tratado de Paris, como órgão jurisdicional da CECA, sendo o responsável pela subsistência e consolidação do Direito da União, vez que atua como instituição garantidora da uniformização da interpretação e aplicação deste último. (RIECHENBERG: 2004; p. 1011). Devido à sua importância, esteve presente nos tratados constitutivos subsequentes, inclusive no mais recente, o Tratado de Lisboa (2007), que dispõe, no art. $19^{\circ}$ do TUE (2007), que: "O Tribunal de Justiça da União Europeia garante o respeito do direito na interpretação e aplicação dos Tratados". Nesse sentido, a atuação do TJ/UE é tão importante que foi responsável por moldar o Direito da União:

$\mathrm{O}$ TJ/UE evoluiu juntamente ao aprofundamento da integração entre os Estados Membros e o fortalecimento do bloco econômico. Mais do que isso, o Tribunal participa, contínua e ativamente, desse processo, através de decisões que moldaram o próprio Direito da União (...). Assim, o reconhecimento da supranacionalidade, os princípios como o efeito direto e a aplicabilidade imediata do Direito europeu, além da primazia sobre os direitos nacionais, originaram-se justamente na jurisprudência do TJ/UE (VIEIRA; ARRUDA: 2018; p. 291).

Por outro lado, considerando que a União Europeia é constituída por diversos países, é inevitável a ocorrência de conflitos de fontes entre o Direito da União e os direitos nacionais, portanto o desenvolvimento dos supramencionados parâmetros foi capaz de elucidar as divergências (MELO; AMARAL JÚNIOR: 2016; p. 548) e garantir a continuidade do processo de integração da União Europeia. Entre os leading cases responsáveis por fixar os entendimentos do TJ/UE sobre a matéria e assim criar os princípios que dão coesão ao ordenamento jurídico europeu, destaca-se o caso Costa c/ ENEL, cuja decisão foi proferida em 15 de junho de 1964, determinando a primazia do Direito Comunitário sobre os direitos internos dos Estados Membros, como forma de assegurar a segurança jurídica. ${ }^{17}$

Cabe destacar que o TJ/UE é regido pelo TUE, TFUE e pelo Estatuto do Tribunal de Justiça, composto na atualidade por 27 juízes (um por Estado Membro) e 11 advogados-gerais. ${ }^{18}$ Sua ju-

17 O caso Costa c/ ENEL teve por objeto questão prejudicial formulada pelo Giudice Conciliatore de Milão, a fim de que o TJ/CE interpretasse os arts. $102^{\circ}, 93^{\circ}, 53^{\circ}$ e $37^{\circ} \mathrm{do}$, à época vigente, Tratado da CEE, cuja decisão foi no sentido de que os atos unilaterais dos Estados Membros, no âmbito do seu direito interno, não poderão ser oponíveis às regras comunitárias. Em outras palavras, há primazia do direito comunitário frente ao direito interno dos Estados Membros. (TRIBUNAL DE JUSTIÇA DA COMUNIDADE EUROPEIA: 1964).

18 Informações sobre a composição do TJ/UE estão no art. $19^{\circ}, n^{\circ} 2$, TUE (2007) que prevê um juiz por Estado Membro, cuja função não é atuar como representante dos interesses de seu país, mas sim contribuir com seu conhecimento sobre o sistema legal do local que provém. Quanto aos advogados-gerais, não obstante o art. $252^{\circ}$ do TFUE (2007) preveja oito membros, o mesmo dispositivo permite a alteração do número através de deliberação do Conselho da União Europeia, o que aconteceu com a Decisão do Conselho 2013/336/UE, de 25.06.2013, ocasião em que houve o aumento para nove advogados-gerais em 2013 e, em 2015, para onze. (CONSELHO DA UNIÃO EUROPEIA: 2013). 
risdição, definida no art. $19^{\circ}, \mathrm{n}^{\circ} 3$ do TUE (2007), abrange: a) recursos interpostos por um Estado Membro, por uma instituição ou por pessoas singulares e coletivas; b) questão prejudicial, interposta a pedido dos órgãos jurisdicionais nacionais sobre a interpretação do Direito da União ou a validade dos atos adotados pelas instituições; c) demais casos previstos pelos Tratados. Já nos arts. $251^{\circ}$ a $281^{\circ}$ do TFUE (2007), há disposições gerais sobre o TJ/UE, sendo que o art. $263^{\circ}$ prevê outras competências atribuídas à instituição referida.

\subsection{A QUESTÃO PREJUDICIAL NA UNIÃO EUROPEIA COMO FERRAMEN- TA PARA A EFETIVAÇÃO DO DIREITO DA UNIÃO}

A questão prejudicial, também designada reenvio prejudicial, é "a via processual que mais contribuiu para afirmação da autoridade doutrinária do Tribunal de Justiça e para a construção pretoriana da União de Direito" (DUARTE: 2017; p. 97), sendo considerada um incidente processual, ${ }^{19}$ vez que suspende o processo no âmbito nacional até a decisão do Tribunal de Justiça. Previsto no art. 267 do TFUE (2007), ${ }^{20}$ o mencionado instituto processual confere competência ao TJ/UE para se pronunciar em caráter prejudicial quanto à interpretação de todos os atos normativos do Direito da União, seja de fonte originária ou derivada, o que abrange, inclusive, os princípios gerais do direito e os acordos celebrados pelo bloco. Ainda, a competência abarca, de maneira mais restrita (DUARTE: 2017; p. 113), a validade dos atos de instituições, órgãos ou organismos da União Europeia apenas no que se refere ao direito derivado.

O referido dispositivo atribuiu ao órgão jurisdicional nacional a faculdade para submissão da questão prejudicial - quando for necessário para resolução do caso concreto - e, também, a obrigatoriedade (VIEIRA: 2013b; p. 38) - em regra, quando não há previsão de recurso judicial ad quem no âmbito do direito interno. (ECEIZABARRENA: 2014; p. 80-103).

Enquanto o desempenho do Tribunal - como última instância para dizer o Direito da União - garante a estabilidade e segurança jurídica do espaço integrado (VIEIRA: 2013b; p. 24), sua

19 Como forma de padronizar o procedimento a ser adotado pelo juiz nacional, ao submeter a questão prejudicial, são elaboradas recomendações aos Estados Membros sobre a proposição em si e disposições gerais da ferramenta prejudicial. A recomendação mais recente publicada é a de n 2016/C 439/01 - Recomendações à Atenção dos Órgãos Jurisdicionais Nacionais, relativas à Apresentação de Processos Prejudiciais. (UNIÃO EUROPEIA: 2012).

20 Art. 267: "O Tribunal de Justiça da União Europeia é competente para decidir, a título prejudicial: a) Sobre a interpretação dos Tratados; b) Sobre a validade e a interpretação dos atos adoptados pelas instituições, os órgãos ou os organismos da União. Sempre que uma questão desta natureza seja suscitada perante qualquer órgão jurisdicional de um dos Estados-Membros, esse órgão pode, se considerar que uma decisão sobre essa questão é necessária ao julgamento da causa, pedir ao Tribunal que sobre ela se pronuncie. Sempre que uma questão desta natureza seja suscitada em processo pendente perante um órgão jurisdicional nacional cujas decisões não sejam susceptíveis de recurso judicial previsto no direito interno, esse órgão é obrigado a submeter a questão ao Tribunal. Se uma questão desta natureza for suscitada em processo pendente perante um órgão jurisdicional nacional relativamente a uma pessoa que se encontre detida, o Tribunal pronunciar-se-á com a maior brevidade possível.”. (TFUE: 2007). 
atuação como instituição judicial coexiste com os tribunais judiciais dos Estados Membros, sem qualquer sorte de hierarquia, já que ambos atuam em cooperação horizontal. Desse modo,

\footnotetext{
(...) ainda que seja certo que compete ao Tribunal de Justiça a última palavra em matéria de interpretação do Direito europeu, também é certo que este não detém a competência exclusiva para a sua aplicação. Isto porque, na verdade, quem aplica o Direito da União, no caso concreto, tratando-se de questões prejudiciais, são as jurisdições nacionais de cada um dos Estados-Membros do bloco econômico. (VIEIRA: 2013b; p. 25).
}

Porém, a cooperação horizontal não significa ausência de separação das funções entre o Tribunal de Justiça e o juiz nacional. Isso porque a atuação do TJ/UE está reservada à interpretação do Direito da União ou, então, à apreciação da validade dos atos, sem que ele possa manifestar-se sobre a interpretação ou aplicação do direito nacional ou sobre como solucionar o caso concreto, cuja função é reservada ao juiz nacional. (DUARTE: 2017, p. 101).

Por fim, afirma-se que a atuação do TJ/UE como garantidor da uniformidade da interpretação e aplicação do Direito da União, por meio da questão prejudicial, é possível em razão de seu efeito vinculante, por tornar a decisão obrigatória ao juiz nacional que submeteu a questão, além de possuir efeito erga omnes, cujo marco temporal inicia-se da publicação oficial da sentença. Ou seja, a contar da publicação, a decisão prejudicial vincula a todas as jurisdições que integram a União Europeia.

\section{O DIREITO À INFORMAÇÃO AMBIENTAL NA UNIÃO EUROPEIA}

O direito à informação ambiental pode ser considerado um dos atributos básicos do mundo contemporâneo, por fornecer ao cidadão relevante ferramenta para a discussão e controle das decisões no contexto governamental e privado, de forma a garantir o futuro que deseja para si e para a sociedade em que está inserido (MILARÉ: 2014; p. 219-223), afora que limitar e censurar o acesso às informações engessam a população, a qual sem conhecimento não poderá influenciar nas decisões que atingem seu meio. (DIZ; DISCACCIATI: 2015; p.78). Contudo, para atingir plenamente o direito ao seu acesso, as informações devem ser revestidas de "veracidade, amplitude, tempestividade e acessibilidade”. (SAMPAIO; WOLD; NARDY: 2003; p. 77). 
A construção do direito à informação no âmbito ambiental e internacional se deu, em especial, com a Declaração de Estocolmo (1972), ${ }^{21}$ sucedida pela Declaração do Rio sobre Ambiente e Desenvolvimento (1992), ${ }^{22}$ criadora do Princípio 10, ${ }^{23}$ que "estabeleceu os três pilares da participação pública em matéria ambiental: acesso à informação, influência da participação popular na tomada de decisão e acesso à justiça”. (LANCHOTTI; DIZ: 2016; p. 136). Assim foi possível que, em 1998, fosse criada a já citada Convenção de Aarhus, a qual incorporou o Princípio 10, antes referido.

Neste sentido, a Convenção de Aarhus (1998) estabelece a obrigação de informar à comunidade e publicar os aspectos ambientais relacionados com as operações ou os projetos de investimento, permitindo, deste modo, incorporar a população no processo de tomada de decisão, de forma democrática. ${ }^{24} \mathrm{O}$ seu objetivo maior é justamente eliminar a proibição de informar e fortalecer o direito ambiental, assegurando à população o acesso à informação ambiental, bem como permi-

21 A Declaração de Estocolmo foi o primeiro documento internacional a tratar o direito de acesso à informação ambiental. Assim, atendendo à necessidade de ser estabelecido um critério, bem como princípios comuns que servissem de guia ou modelo para os Estados, destinados a preservar o meio ambiente, trouxe no Princípio $\mathrm{n}^{\circ} 19$ o registro do direito referido, nos seguintes termos: "Es indispensable una labor de educación en cuestiones ambientales, dirigida tanto a las generaciones jóvenes como a los adultos y que preste la debida atención al sector de población menos privilegiado, para ensanchar las bases de una opinión pública bien informada y de una conducta de los individuos, de las empresas y de las colectividades inspiradas en el sentido de su responsabilidad en cuanto a la protección y mejoramiento del medio en toda su dimensión humana. Es también esencial que los medios de comunicación de masas eviten contribuir al deterioro del medio humano y difundan, por el contrario, información de carácter educativo sobre la necesidad de protegerlo y mejorarlo, a fin de que el hombre pueda desarrollarse en todos los aspectos". (VILLANUEVA: 2008; p. 336-337). No mesmo sentido, o Princípio $n^{\circ} 20$ determina que os países devem fomentar a pesquisa e o desenvolvimento científicos referentes aos problemas ambientais, prescrevendo o livre intercâmbio de informação científica atualizada, em matéria ambiental, como medida para facilitar o acesso à informação ambiental.

22 A Agenda 21 Global, documento da ONU que acompanhou a Declaração do Rio sobre Meio Ambiente e Desenvolvimento de 1992 previu, no Capítulo 40, lineamentos estratégicos para a adoção de políticas públicas, pelos Estados, para viabilizar o direito de acesso à informação ambiental, de modo a facilitar o processo de tomada de decisões, reduzindo as diferenças em matéria de dados e aperfeiçoando a disponibilidade da informação. (UNITED NATIONS: 1992).

23 Por sua vez, o Princípio 19 da Declaração do Rio sobre Meio Ambiente e Desenvolvimento (1992) trouxe o acesso à informação ambiental, colocando o Estado (e não o indivíduo) como titular desse direito, nos seguintes termos: "Os Estados deverão proporcionar a informação pertinente e notificar previamente e de forma oportuna os Estados que possam se ver afetados por atividades passíveis de ter consideráveis efeitos ambientais nocivos transfronteiriços, e deverão celebrar consultas com os mesmos em data antecipada.”. (UNITED NATIONS: 1993; p. 11).

24 O Secretário Geral da Convenção de Aarhus, na época de sua assinatura, em 1998, destacou a importância do tratado para os países em desenvolvimento, sustentando que: "La Convención no es sólo una poderosa arma de lucha para proteger el medio ambiente, sino que también una importante herramienta para la democracia, especialmente en países que recientemente han incorporado sistemas democráticos de gobiernos, donde es importante establecer principios de transparencia, responsabilidad e involucrar a la sociedad para asegurar estabilidad y seguridad nacional.”. (VILLANUEVA: 2008; p. 339-340). 
tindo aos Estados a tomada de medidas para evitar situações de desastre ambiental provocadas pela desinformação. (VILLANUEVA: 2008; p. 339-340). Oportuno ressaltar que, embora o presente artigo se refira à Convenção de Aarhus (1998) sob o aspecto do direito à informação ambiental, essa também abrange a participação pública e o acesso à justiça.

Na União Europeia, o direito à informação ambiental estava, antes mesmo da Convenção de Aarhus (1998), previsto pela Diretiva 90/313/CEE, porém foi com a ratificação da citada Convenção que o conceito de informação ambiental foi ampliado e, após, revisto pela Diretiva 2003/4/CE e pelo Regulamento $n^{\circ} 1367 / 2006$, instrumentos jurídicos que auxiliaram na adequação das previsões da Convenção à legislação comunitária.

A fim de conceituar a informação ambiental, cabível a utilização do documento jurídico mais recente adotado pelo bloco sobre o tema, o Regulamento $\mathrm{n}^{\circ} 1367 / 2006$, que em seu art. $2^{\circ}$, n. 1 , "d", qualifica a informação ambiental nos seguintes termos:

d) «Informação sobre ambiente», qualquer informação sob forma escrita, visual, sonora, electrónica ou qualquer outra forma material relativa: i) ao estado dos elementos do ambiente, como o ar e a atmosfera, a água, o solo, a terra, a paisagem e as áreas de interesse natural, incluindo as zonas húmidas, as zonas litorais e marinhas, a diversidade biológica e os seus componentes, incluindo os organismos geneticamente modificados, e a interacção entre estes elementos; ii) a factores como as substâncias, a energia, o ruído, as radiações ou os resíduos, incluindo resíduos radioactivos, as emissões, as descargas e outras libertações para o ambiente, que afectem ou possam afectar os elementos do ambiente referidos no ponto i); iii) a medidas (incluindo as administrativas) como as políticas, a legislação, os planos, os programas, os acordos ambientais e as acções que afectem ou possam afectar os elementos e factores referidos nos pontos i) e ii), bem como as medidas ou acções destinadas a proteger esses elementos; iv) a relatórios sobre a aplicação da legislação ambiental; v) a análises de custos/benefícios e outras análises e cenários económicos utilizados no âmbito das medidas e acções referidas no ponto iii); vi) ao estado da saúde e da segurança das pessoas, incluindo a contaminação da cadeia alimentar, quando tal seja relevante, as condições de vida, os locais de interesse cultural e as construções, na medida em que sejam ou possam ser afectados pelo estado dos elementos do ambiente referidos no ponto i), ou, através desses elementos, por qualquer dos elementos referidos nos pontos ii) e iii).

Em relação ao direito à informação ambiental conferido ao consumidor, embora a Diretiva 2003/4/CE e o Regulamento $n^{\circ} 1367 / 2006$ sejam silentes a respeito, é importante destacar que a Convenção de Aarhus (que foi devidamente ratificada pela União Europeia, como já aludido pela Decisão $n^{\circ}$ 2005/370/CE) garantiu a ele, de forma expressa, o seu direito de acesso à informação de caráter ambiental, no art. $5^{\circ}$, n. 8 , ao afirmar que:

Cada Parte deve conceber mecanismos destinados a garantir a colocação à disposição do público de informações suficientes sobre os produtos de uma forma que permita aos consumidores fazer as suas opções em matéria ambiental com conhecimento de causa. (COMISSÃO ECONÔMICA DAS NAÇÕES UNIDAS PARA A EUROPA: 1998).

Dessa forma, o consumidor poderá, em posse das informações, escolher o que consumir (AYROSA; BORGES: 2018; p. 392-393) privilegiando, assim, o consumo sustentável, consciente e responsável, conceito inicialmente previsto na Resolução 53/1995 da ONU, hoje contemplado 
no ODS 12 da Agenda 2030 para o Desenvolvimento Sustentável (ONU: 2015), bem como nas Diretrizes das Nações Unidas de Proteção do Consumidor, de 2015.25

No entanto, a disponibilização das informações não é absoluta, vez que a própria Convenção previu hipóteses, no art. $4^{\circ}$, n. 3 e 4, em que a solicitação de informação sobre o ambiente poderá ser objeto de recusa, devendo ser analisado o caso concreto, com base em interpretação restritiva das hipóteses de recusa, previstas em lei, sopesando o interesse público na divulgação.

\section{O DIREITO À INFORMAÇÃO AMBIENTAL, A PARTIR DA ATUAÇÃO DO TRIBUNAL DE JUSTIÇA DA UNIÃO EUROPEIA}

Desde a edição das normas que consagraram o "princípio do direito do público ao acesso a informações em matéria de ambiente" (TRIBUNAL DE JUSTIÇA DA UNIÃO EUROPEIA: 2017; p. 01), o TJ/UE mostrou-se essencial na composição da jurisprudência comunitária sobre o tema, especialmente, com a questão prejudicial. De modo a sustentar a referida afirmação, citam-se os casos: C-266/09, C-524/09, C-71-14, C-442/14 e C-664/15, a seguir analisados, todos coletados na jurisprudência do Tribunal referido. Para realizar o recorte dos julgados, as opções de pesquisa foram limitadas ao TJ/UE, em sede de questão prejudicial, enquanto os termos utilizados foram: "Diretiva 2003/4/CE", "Diretiva 90/313/CEE", "Convenção de Aarhus", "Regulamento 1367/2006", "informação ambiental” e "consumo sustentável”.

Cita-se como primeiro exemplo da aplicação da Convenção de Aarhus (1998), na União Europeia, a questão prejudicial referente ao assunto C-266/09, julgada em 16 de dezembro de 2010. Na ocasião, o Governo dos Países Baixos atendeu ao pedido formulado pela Bayer CropScience BV para a alteração do teor máximo permitido de resíduos do pesticida propamocarbe (encontrado, por exemplo, em alfaces). Em razão disso, três organizações ambientais holandesas solicitaram informações sobre os estudos utilizados para proceder à alteração. Porém, o pedido foi objeto de recusa sob o fundamento que as informações industriais e comerciais eram confidenciais.

Irresignadas, as organizações ambientais recorreram à jurisdição nacional, a qual, por sua vez, propôs questão prejudicial ao TJ/UE, requerendo a intepretação do conceito de "informação sobre o ambiente", previsto na Diretiva 2003/4/CE. Em sua decisão, o TJ/UE declarou que as informações em relação à utilização de produtos fitofarmacêuticos estão inclusas no conceito de "informação sobre o ambiente" e, além disso, que as autoridades competentes para fornecer as informações ambientais, deparando-se com conflitos entre interesse público e particular, devem considerar o caso concreto, sendo facultado ao legislador nacional estabelecer critérios a fim de facilitar o equilíbrio dos interesses mencionados. (TRIBUNAL DE JUSTIÇA: 2010a)

25 As Diretrizes das Nações Unidas de Proteção ao Consumidor foram estabelecidas pela Resolução A/ RES/39/248 da Assembleia Geral, de 09 de abril de 1985, servindo de inspiração e parâmetro para todos os países no tocante à adoção de medidas de proteção ao consumidor. Em 22 de dezembro de 2015, por meio da Resolução A/RES/70/186, as Diretrizes foram atualizadas, a fim de acompanhar a evolução nas relações de consumo e seguir estabelecendo princípios relevantes para a proteção dos consumidores. Destaca-se que o Objetivo "H" das Diretrizes é a promoção do consumo sustentável - relacionando-se diretamente ao Princípio n 12 da Agenda 2030. (UNITED NATIONS: 2016). 
Outra questão prejudicial que envolve o conceito de informação ambiental, assim como a recusa no fornecimento de informações é o assunto C-524/09, julgado em 22 de dezembro de 2010. Na oportunidade, a cidade de Lyon solicitou informações ao órgão nacional responsável pelo registro das licenças de emissão de gases com efeito estufa sobre o volume destas emissões no território francês, pedido que, por sua vez, foi indeferido, sob a justificativa de que a Diretiva 2003/4/CE não abrangeria a comunicação de tais dados (relativos ao Protocolo de Quioto), ${ }^{26}$ situação confirmada pelo TJ/UE, que ressaltou que a interpretação para a recusa de informações deverá ser sempre restritiva. (TRIBUNAL DE JUSTIÇA: 2010b).

Já a questão prejudicial contida no assunto C-71/14, julgada em 06 de outubro de 2015, envolve as taxas cobradas pelo fornecimento de informações ambientais, com incertezas quanto ao que pode ser considerado no cálculo, repercutindo, em outras palavras, no acesso às informações. À época, a empresa PSG Eastbourne, atuante no ramo de pesquisas imobiliárias, requereu ao County Council informações sobre ambiente que foram devidamente fornecidas mediante pagamento de taxa. No entanto, a empresa PSG Eastbourne prestou queixa por entender que as taxas, na forma em que foram calculadas, desrespeitavam a Diretiva 2003/4/CE, situação confirmada pelo Information Commissioner.

Diante disso, as partes buscaram a tutela jurisdicional nacional, que, por sua vez, submeteu questão prejudicial ao tribunal comunitário, suscitando, entre outros pedidos, o esclarecimento da dúvida em relação ao que poderia ser incluído na taxa, para ser considerada de montante razoável. Em síntese, ao interpretar a Diretiva 2003/4/CE, o TJ/UE declarou que as taxas cobradas no fornecimento de informação sobre ambiente não poderão incluir custos decorrentes da simples manutenção de uma base de dados, embora possa considerar o tempo gasto pelos funcionários para responder aos pedidos de informações individuais, desde que o valor seja razoável, a fim de evitar obstaculizar o acesso às informações ambientais. (TRIBUNAL DE JUSTIÇA DA UNIÃO EUROPEIA: 2015)

Por sua vez, a questão prejudicial originada no assunto C-442/14, cujo julgamento ocorreu em 23 de novembro de 2016, envolveu a controvérsia na interpretação do conceito "informações sobre emissões para o ambiente". No caso, a autoridade neerlandesa College voor de toelating van gewasbeschermingsmiddelen en biociden (responsável por conceder e alterar as autorizações de produtos fitofarmacêuticos e biocidas no mercado neerlandês), autorizou a utilização de pesticidas

26 Aberto para assinatura em 16 de março de 1998 e com sua entrada em vigor em 16 de fevereiro de 2005, o Protocolo de Quioto (UNITED NATIONS: 1998) é considerado um tratado complementar da ConvençãoQuadro das Nações Unidas sobre a Mudança do Clima (1992). Foi responsável por criar diretrizes, a fim de reduzir a emissão dos gases causadores do efeito estufa e promover o desenvolvimento sustentável, estabelecendo, para tanto, metas específicas aos signatários, bem como uma meta coletiva. Em um primeiro momento, o objetivo era a redução de 5,2\% de emissão de gases de efeito estufa até 2012 , em relação aos índices de 1990, no entanto a meta não foi alcançada, razão pela qual, em 08 de dezembro de 2012, durante a realização da COP 18 (Conferência das Nações Unidas sobre Mudanças Climáticas em Doha - Qatar), o Protocolo recebeu uma emenda, conhecida como "Emenda de Doha" (UNITED NATIONS: 2012), pela qual os membros estabeleceram um novo período para atingir o objetivo do documento, de 2013 a 2020. Cabe destacar que até 06 de janeiro de 2020, o tratado aditivo possuía 136 depositários, sendo necessário o total de 144 para a entrada em vigor. 
cuja substância ativa era imidaclopide. Em razão disso a Stichting De Bijenstichting (Associação Neerlandesa para Proteção de Abelhas) solicitou informações sobre as autorizações concedidas, com base na Diretiva 2003/4/CE.

Contudo, o pedido foi indeferido sob a alegação de que a Diretiva não abrangia informações sobre emissões de pesticidas. Esse indeferimento motivou a submissão da questão prejudicial ao TJ/UE para que, entre em outros pedidos, fosse solicitada a interpretação do conceito "emissões para o ambiente" de modo a incluir, ou não, os dados que estimam as emissões do produto no ambiente. Em sua decisão, o TJ/UE declarou que as informações sobre a liberação dos produtos no meio ambiente, assim como as substâncias que contêm efeitos a longo prazo, são abrangidos pela Diretiva - sendo possível, no entanto, a omissão de dados que não envolvem as emissões para o ambiente. (TRIBUNAL DE JUSTIÇA: 2016).

Não obstante a ausência de acórdãos prejudiciais após 2016, cabe destacar que até junho de 2019 verificou-se que o TJ/UE já realizou interpretações sobre o tema, viabilizando, portanto, a posterior aplicação do Direito da União, em especial do direito à informação ambiental, pelo juiz nacional. Destaca-se, no entanto, como ponto negativo, a ausência de casos com a figura direta do consumidor enquanto beneficiário do direito à informação ambiental, situação não prevista expressamente na Diretiva 2003/4/CE e no Regulamento $n^{\circ} 1367 / 2006$, embora tal prerrogativa esteja prevista na Convenção de Aarhus (1998) e seja notório o seu impacto na vida do consumidor e do cidadão europeu.

\section{CONSIDERAÇÕES FINAIS}

O principal objetivo que guiou o presente artigo foi demonstrar a importância do direito à informação ambiental no contexto da sociedade contemporânea, especialmente na União Europeia, além disso, destacar seu papel como aliado na promoção do desenvolvimento e consumo sustentáveis, metas da Agenda 2030 para o Desenvolvimento Sustentável da ONU. Constatou-se que os Estados, para promoverem a proteção e preservação do meio ambiente, de forma efetiva, deverão prestar informações ambientais a seus cidadãos e, no que nos interessa, aos potenciais consumidores que se encontram ou se dirigem aos seus territórios, para que possuam mais ferramentas que os auxiliem no processo de tomada de decisão sobre os produtos que irão consumir, a partir de critérios ambientalmente sustentáveis.

No entanto, mesmo sendo um direito amplamente reconhecido - e de necessária existência -, sua efetivação é complexa, como demonstrado pela evolução na legislação sobre o tema pesquisado, tanto no domínio internacional, quanto na esfera regional conformada pela União Europeia. Isso confirma a importância da atuação do TJ/UE, de modo a uniformizar a interpretação sobre o assunto no âmbito do bloco, utilizando, para tanto, a questão prejudicial, que igualmente se destina a assegurar a aplicação da Convenção de Aarhus, ratificada pelo processo de integração referido, bem como os instrumentos legais comunitários que incorporaram o direito à informação ambiental, o que confirma a hipótese de trabalho apresentada no começo desta pesquisa e responde ao problema de pesquisa apresentado. 
Por fim, cabe referir que, embora a Convenção de Aarhus discorra sobre o direito fundamental do consumidor de receber informações em matéria ambiental, que guiarão as suas escolhas futuras, não foi localizado nenhum caso apreciado pelo TJ/UE sobre o tema, vez que a maioria das questões prejudiciais encontradas na pesquisa jurisprudencial envolviam o conceito de "informação sobre ambiente" e "autoridade pública", além das hipóteses de recusa de informações e possibilidade de cobrança de taxas para o fornecimento dos dados requeridos afora a questão do acesso à justiça em matéria ambiental - também garantido pela Convenção -, mas sem abordar a temática referida, essencial para a consolidação do direito de acesso à informação ambiental. Espera-se que, em um futuro não muito distante, o TJ/UE possa ser convocado pelo juiz nacional dos Estados Membros a manifestar-se sobre a interpretação do direito em evidência, a partir da previsão da Convenção de Aarhus, destinada a brindar ferramentas ao consumidor para que ele possa optar pelo consumo consciente de produtos sustentáveis.

Apesar disso, verifica-se que os objetivos do trabalho foram contemplados, vez que a questão prejudicial revela-se como sendo a ferramenta apta para fins de uniformização do direito à informação ambiental na União Europeia, além de servir para fins de cooperação jurídica entre o TJ/UE e os tribunais nacionais dos agora 27 Estados Membros da União Europeia.

\section{REFERÊNCIAS}

ARAGÃO, Alexandra. A proteção do ambiente em rede: uma estratégia nacional, uma responsabilidade Europeia. Periódico do CIEDA e do CIEJD. n. 1. jun./dez. 2009. Disponível em: http://debatereuropa.europe-direct-aveiro.aeva.eu/. Acesso em: 23 mar. 2019.

AYROSA, Igor Feitosa Lacôrte; BORGES, Liliane de Moura. Exercício do direito à informação e consumo consciente: contribuições da economia comportamental para o direito do consumidor. Revista de Direito do Consumidor. v. 119. 2018. p. 385-410.

BASSO, Maristela. Integração econômica e proteção ambiental: livre circulação de mercadorias e proteção ambiental no Mercosul. In: BASSO, Maristela (org.). Mercosul: seus efeitos jurídicos, econômicos e políticos nos estados-membros. Porto Alegre: Livraria do Advogado, 1995. cap. 4. p. 193-233.

BORCHARDT, Klaus-Dieter. $O A B C$ do direito da União Europeia. Luxemburgo: Serviço das Publicações da União Europeia, 2017. Disponível em: https://publications.europa.eu/pt/publication-detail/-/publication/ 5d4f8cde-de25-11e7-a506-01aa75ed71a1/language-pt. Acesso em: 1 mar. 2019.

COMISSÃO ECONÔMICA DAS NAÇÕES UNIDAS PARAA EUROPA (UNECE). Convenção de Aarhus. 1998. Jornal Oficial da União Europeia: 2005. Disponível em: https://eur-lex.europa.eu/legal-content/PT/ TXT/?uri=uriserv:OJ.L_2005.124.01.0001.01.POR\&toc=OJ:L:2005:124:TOC\#L_2005124PT.01000401. Acesso em: 10 fev. 2020.

COMISSÃO EUROPEIA. Comunicação da Comissão ao Parlamento Europeu, ao Conselho, ao Comitê Econômico e Social Europeu e ao Comitê das Regiões: uma parceria global para a erradicação da pobreza e o desenvolvimento sustentável pós-2015. Bruxelas: 2015. Disponível em: https://eur-lex.europa.eu/ resource.html?uri=cellar:afc5ef38-ad24-11e4-b5b2-01aa75ed71a1.0010.02/DOC_1\&format=PDF. Acesso em: 10 fev. 2020.

COMISSÃO EUROPEIA. Documento de Reflexão: para uma Europa sustentável até 2030. Bruxelas, 2019. Disponível em: https://ec.europa.eu/transparency/regdoc/rep/1/2019/PT/COM-2019-22-F1-PT-MAINPART-1.PDF. Acesso: 11 fev. 2020.

COMUNIDADES EUROPEIAS. Tratado de Maastricht, de 7 de fevereiro de 1992. Jornal Oficial das Comunidades Europeias: 1992. Disponível em: https://eur-lex.europa.eu/legal-content/PT/ 
A efetivação do direito à informação ambiental, por meio da questão prejudicial...

VIEIRA, L. K.; FRAINER, V. M.

TXT/?uri=CELEX:11992M/TXT. Acesso em: 8 jun. 2019.

CONSELHO DA UNIÃO EUROPEIA. Acordo sobre a saída do Reino Unido da Grã-Bretanha e da Irlanda do Norte da União Europeia e da Comunidade Europeia da Energia Atómica. Bruxelas, 18 de outubro de 2019. Disponível em: https://data.consilium.europa.eu/doc/document/XT-21054-2019-INIT/pt/pdf. Acesso em: 06 fev. 2020.

CONSELHO DA UNIÃO EUROPEIA. Brexit: Conselho adota decisão relativa à celebração do Acordo de Saída. Data da publicação: 30 de janeiro de 2020. Disponível em: https://www.consilium.europa.eu/ pt/press/press-releases/2020/01/30/brexit-council-adopts-decision-to-conclude-the-withdrawal-agreement/. Acesso em: 6 fev. 2020.

CONSELHO DA UNIÃO EUROPEIA. Decisão (UE) 2018/881 do Conselho da União Europeia, de 18 de junho de 2018, que contém um pedido à Comissão no sentido de apresentar um estudo sobre as opções da União para responder às conclusões do Comité de Avaliação do Cumprimento da Convenção de Aarhus no processo ACCC/C/2008/32 e, se adequado à luz do resultado do estudo, para apresentar uma proposta de regulamento do Parlamento Europeu e do Conselho que altere o Regulamento (CE) $n^{\circ}$ 1367/2006. Jornal Oficial da União Europeia: 2018. Disponível em: https://eur-lex.europa.eu/legal-content/PT/TXT/ PDF/?uri=CELEX:32018D0881\&from=EN. Acesso em: 11 fev. 2020.

CONSELHODAUNIÃOEUROPEIA.Decisão 2005/370/CE. 17 de fevereiro de 2005. JornalOficial da União Europeia: 2005. Disponível em: https://eur-lex.europa.eu/legal-content/PT/TXT/?uri=celex:32005D0370. Acesso em: 25 abr. 2019.

CONSELHO DA UNIÃO EUROPEIA. Decisão 2013/336/UE. Jornal Oficial da União Europeia: 2013. Disponível em: https://eur-lex.europa.eu/LexUriServ/LexUriServ.do?uri=OJ:L:2013:179:0092:0092:PT:PDF. Acesso em: 10 abr. 2019.

CONSELHO DAS COMUNIDADES EUROPEIAS. Diretiva 90/313/CEE. Jornal Oficial das Comunidades Europeias: 1990.Disponívelem:https://eur-lex.europa.eu/legal-content/PT/TXT/?uri=CELEX\%3A31990L0313. Acesso em: 4 abr. 2019.

CONSELHO EUROPEU. Conselho Europeu de Copenhaga (1993). Disponível em: https://www.consilium.europa.eu/media/21226/72926.pdf/. Acesso em: 10 abr. 2019.

CONSELHO EUROPEU. Conselho Europeu de Madrid (1995). Disponível em: https://www.consilium. europa.eu/media/21180/madrid-conselho-europeu.pdf/. Acesso em: 10 abr. 2019.

DIZ, Jamile Bergamaschine Mata; DISCACCIATI, Ana Clara Gonçalves. Acesso à informação ambiental: por um novo paradigma de participação. Revista Direito e Liberdade. v. 17, n. 3. p. 71-113. set./dez. 2015. Disponível em: https://www.esmarn.tjrn.jus.br/revistas/index.php/revista direito_e liberdade/article/ view/956. Acesso em: 14 fev. 2019.

DUARTE, Maria Luísa. Direito do Contencioso da União Europeia. Lisboa: AAFDL, 2017.

DUARTE, Maria Luísa. O tempo e a transposição de diretivas no direito da União Europeia. In: Estudos em homenagem a Miguel Galvão Teles. Coimbra: Almedina, 2012. v. 1. p. 423-439.

ECEIZABARRENA, Juan Ignacio Ugartemendia. La autonomía de la cuestión prejudicial europea ante el Derecho interno. European inklings (EUi): IV - La cuestión prejudicial europea. 2014.

LANCHOTTI, Andressa de Oliveira; DIZ, Jamile Bergamaschine Mata. Direito de acesso à informação ambiental: da formalidade à efetividade dos direitos de acesso. Revista de Direito e Sustentabilidade. Curitiba, v. 2, n. 2. jul/dez. 2016.

MACHADO, Diego Pereira. Direito da União Europeia. São Paulo: Saraiva, 2013.

MELO, Lucas Fonseca e; AMARAL JÚNIOR, José Levi Mello do. O efeito direto das diretivas e os direitos fundamentais. Revista de Direito Internacional. Brasília, v. 13, n. 2, 2016.

MILARÉ, Édis. Direito do ambiente. 9. ed. São Paulo: Revista dos Tribunais, 2014. 
A efetivação do direito à informação ambiental, por meio da questão prejudicial...

VIEIRA, L. K.; FRAINER, V. M.

ORGANIZAÇÃO DAS NAÇÕES UNIDAS (ONU). Assembleia Geral. Transformando Nosso Mundo: A Agenda 2030 para o Desenvolvimento Sustentável. Nova York: ONU, [2015]. Disponível em: https://nacoesunidas.org/wp-content/uploads/2015/10/agenda2030-pt-br.pdf. Acesso em: 02 abr. 2019.

PARLAMENTO EUROPEU E CONSELHO DA UNIÃO EUROPEIA. Diretiva 2003/4/CE. Jornal Oficial da União Europeia: 2003. Disponível em: http://data.europa.eu/eli/dir/2003/4/oj. Acesso em: 04 abr. 2019.

PARLAMENTO EUROPEU E CONSELHO DA UNIÃO EUROPEIA. Regulamento (CE) $n^{\circ}$ 1367/2006. Jornal Oficial da União Europeia: 2006. Disponível em: https://eur-lex.europa.eu/eli/reg/2006/1367/oj. Acesso em: 04 abr. 2019.

PARLAMENTO EUROPEU E CONSELHO DA UNIÃO EUROPEIA. Regulamento (UE) 2017/1601 do Parlamento Europeu e do Conselho da União Europeia, de 26 de setembro de 2017, que institui o Fundo Europeu para o Desenvolvimento Sustentável (FEDS), a Garantia FEDS e o Fundo de Garantia FEDS. Jornal Oficial da União Europeia: 2017. Disponível em: https://eur-lex.europa.eu/legal-content/PT/TXT/ PDF/?uri=CELEX:32017R1601\&from=EN. Acesso em: 11 fev. 2020.

PARLAMENTO EUROPEU E CONSELHO DA UNIÃO EUROPEIA. Regulamento (UE) 2019/2088 do Parlamento Europeu e do Conselho da União Europeia, de 27 de novembro de 2019, relativo à divulgação de informações relacionados com a sustentabilidade no setor dos serviços financeiros. Jornal Oficial da União Europeia: 2019. Disponível em: https://eur-lex.europa.eu/legal-content/PT/ TXT/?uri=CELEX\%3A32019R2088. Acesso: 11 fev. 2020.

PARLAMENTO EUROPEU. Resolução do Parlamento Europeu, de 12 de maio de 2016, sobre o acompanhamento e a revisão da Agenda 2030 (2016/2696(RSP)). Jornal Oficial da União Europeia: 2016. Disponível em: https://eur-lex.europa.eu/legal-content/PT/TXT/?uri=CELEX:52016IP0224. Acesso em: 10 fev. 2020.

RIECHENBERG, Kurt. El proceso prejudicial en la Unión Europea. Anuario de Derecho Constitucional Latinoamericano. Montevideo, 2004.

SAMPAIO, Izabel Cristina da Silva. Informação ambiental: a Convenção de Aarhus e seu contributo no âmbito da União Europeia. Revista do Instituto do Direito Brasileiro. n. 12. 2013. p. 14233-14298. Disponível em: https://www.cidp.pt/revistas/ridb/2013. Acesso em: 04 abr. 2019.

SAMPAIO, José Adércio Leite; WOLD, Chris; NARDY, Afrânio José Fonseca. Princípios de direito ambiental. Belo Horizonte: Del Rey, 2003.

SUSTAINABLE DEVELOPMENT SOLUTIONS NETWORK (SDSN) AND INSTITUTE FOR EUROPEAN ENVIRONMENTAL POLICY (IEEP). 2019 Europe Sustainable Development Report. 2019. Disponível em: https://s3.amazonaws.com/sustainabledevelopment.report/2019/2019 europe sustainable development report.pdf. Acesso: 11 fev. 2020.

TRIBUNAL DE JUSTIÇA DA COMUNIDADE EUROPEIA. Acórdão Flaminio Costa c/ ENEL (Assunto C-6/64). Data de julgamento: 15 de julho de 1964. Disponível em: http://curia.europa.eu/juris/showPdf. jsf?text $=\&$ docid $=87399 \&$ pageIndex $=0 \&$ doclang $=$ PT \&mode $=1$ st \&dir=\&occ=first \&part $=1 \& c i d=220375$. Acesso em: 03 abr. 2019.

TRIBUNAL DE JUSTIÇA DA UNIÃO EUROPEIA. Acórdão Bayer CropScience AS-NV e Stichting De Bijenstichting contra College voor de toelating van gewasbeschermingsmiddelen en biociden. (Assunto C-442/14). Data do julgamento: 23 de novembro de 2016. Disponível em: http://curia.europa.eu/juris/document/document.jsf?text $=\&$ docid $=185542 \&$ pageIndex $=0 \&$ doclang $=P T \&$ mode $=1$ st \&dir $=\& o c c=$ first \&par$\mathrm{t}=1 \& \mathrm{cid}=760628$. Acesso em: 29 abr. 2019.

TRIBUNAL DE JUSTIÇA DA UNIÃO EUROPEIA. Acórdão East Sussex County Coucil e Information Commissioner. (Assunto C-71/14). 06 de outubro de 2015. Disponível em: http://curia.europa.eu/juris/document $/$ document.jsf?text $=\&$ docid $=169183 \&$ pageIndex $=0 \&$ doclang $=p t \&$ mode $=1$ st $\&$ dir $=\& o c c=$ first\&par$\underline{\mathrm{t}=1 \& \mathrm{cid}=3641669}$. Acesso em: 29 abr. 2019. 
A efetivação do direito à informação ambiental, por meio da questão prejudicial...

VIEIRA, L. K.; FRAINER, V. M.

TRIBUNAL DE JUSTIÇA DA UNIÃO EUROPEIA. Acórdão Protect Natur-, Arten- und Landschaftsschutz Umweltorganisation e Bezirkshauptmannschaft Gmünd. (C-664/15). Data do julgamento: 20 dezembro de 2017. Disponível em: http://curia.europa.eu/juris/document/document.jsf?text=\&docid=198046\&pageIn-

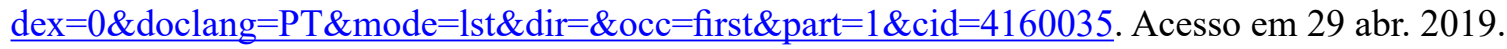

TRIBUNAL DE JUSTIÇA DA UNIÃO EUROPEIA. Acórdão Stichting Natuur en Milieu e outros. (Assunto C-266/09). Data do julgamento: 16 de dezembro de 2010a. Disponível em: http://curia.europa.eu/juris/document/document print.jsf?docid $=79382 \&$ text $=\&$ dir $=\&$ doclang $=$ PT \&part $=1 \&$ occ $=$ first\&mode $=1$ st \&pageIndex $=0 \& c i d=759480$. Acesso em: 29 abr. 2019.

TRIBUNAL DE JUSTIÇA DA UNIÃO EUROPEIA. Acórdão Ville de Lyon c/ Caisse des dépôts et consignations. (Assunto C-524/09). Data do julgamento: 22 de dezembro de 2010b. Disponível em: http:// curia.europa.eu/juris/document/document.jsf?text $=\&$ docid $=83446 \&$ pageIndex $=0 \&$ doclang $=$ PT \&mode $=1$ s$\underline{\mathrm{t} \& \mathrm{dir}=\& \mathrm{occ}=\text { first\&part }=1 \& \mathrm{cid}=760163}$. Acesso em: 29 abr. 2019.

TRIBUNAL DE JUSTIÇA DA UNIÃO EUROPEIA. Ficha temática: acesso do público às informações sobre ambiente. 2017. p. 01. Disponível em: https://curia.europa.eu/jcms/upload/docs/application/pdf/201805/fiche thematique - environnement_- pt.pdf. Acesso em: 28 abr. 2019.

UNIÃO EUROPEIA. Tratado de Lisboa, de 13 de dezembro de 2007. Disponível em: https://eur-lex.europa.eu/legal-content/PT/TXT/PDF/?uri=CELEX:12007L/TXT\&from=PT. Acesso em: 08 jun. 2019.

UNIÃO EUROPEIA. Carta dos Direitos Fundamentais da União Europeia (CDFUE). Jornal Oficial das Comunidades Europeias: 2000. Disponível em: https://eur-lex.europa.eu/legal-content/PT/TXT/ PDF/?uri=CELEX:12016P/TXT\&from=FR. Acesso em: 11 fev. 2020.

UNIÃO EUROPEIA. Recomendações à atenção dos órgãos jurisdicionais nacionais, relativas à apresentação de processos judiciais. Jornal Oficial da União Europeia: 2012. Disponível em: https://eur-lex.europa. eu/LexUriServ/LexUriServ.do?uri=OJ:C:2012:338:0001:0006:PT:PDF. Acesso em: 11 fev. 2020.

UNITED NATIONS. Doha Amendment to the Kyoto Protocol. Doha, 8 December 2012. Disponível em: https://unfccc.int/process/the-kyoto-protocol/the-doha-amendment. Acesso em: 10 fev. 2020.

UNITED NATIONS. Kyoto Protocol to the United Nations Framework Convention on Climate Change. 1998. Disponível em: https://unfccc.int/resource/docs/convkp/kpeng.pdf. Acesso em: 10 fev. 2020.

UNITED NATIONS. Report of the United Nations Conference on Environment and Development. Rio de Janeiro, Brazil, 3 to 14 June 1992. New York, 1993. Disponível em: https://www.un.org/esa/dsd/agenda21/ Agenda\%2021.pdf. Acesso em: 10 fev. 2020. p. 10-11.

UNITED NATIONS. United Nations Conference on Environment \& Developmennt: Rio de Janeiro, Brazil, 3 to 14 June 1992 - Agenda 21. Rio de Janeiro: 1992. Disponível em: https://sustainabledevelopment.un.org/ content/documents/Agenda21.pdf. Acesso em: 10 fev. 2020.

UNITED NATIONS. United Nations Guidelines for Consumer Protection. New York and Geneva, 2016. Disponível em: https://unctad.org/en/PublicationsLibrary/ditccplpmisc2016d1_en.pdf. Acesso em: 08 fev. 2020.

VIEIRA, Luciane Klein. Interpretação e Aplicação Uniforme do Direito da Integração: União Europeia, Comunidade Andina, Sistema da Integração Centro-americana e MERCOSUL. Curitiba: Juruá, 2013b.

VIEIRA, Luciane Klein. La hipervulnerabilidad del consumidor transfronterizo y la función material del Derecho Internacional Privado. 1. ed. Buenos Aires: La Ley, 2017.

VIEIRA, Luciane Klein. Protección internacional del consumidor: processos de escassa cuantía en los litigios transfronterizos. Buenos Aires: Editorial B de F, 2013a.

VIEIRA, Luciane Klein; ARRUDA, Elisa. A relação entre o grau de integração econômica e o sistema de solução de controvérsias: um estudo comparativo entre a União Europeia e o Mercosul. Revista de Direito Internacional. Brasília, v. 15, n. 2, 2018.

VILLANUEVA, Claudia. Derecho de acceso a la información ambiental, antecedentes internacionales y 
legislación nacional. In: DEVIA, Leila (Coord.) Nuevo Rumbo Ambiental. Buenos Aires/Madrid: Ciudad Argentina, 2008.

ZALDUENDO, Susana Czar de. Integración: nociones generales integración económica e integración regional. In: NEGRO, Sandra C. (Dir.). Derecho de la Integración: Manual. Buenos Aires: Editorial B de F, 2013. p. 3-24.

Data de submissão do artigo: Agosto de 2019

Data de aceite do artigo: Março de 2020(*)

\section{(*) NOTA TÉCNICA:}

Esclarecemos que, em razão do ataque de hackers a que foi submetido o conjunto de periódicos da Universidade Federal de Goiás (UFG), ao que se inclui a Revista da Faculdade de Direito da UFG (RFD/UFG), os artigos ordenados entre os números 21-30, referentes ao volume 43, embora tenham sido recebidos e aceitos em datas distintas e anteriores, dado o perecimento de suas referências, foram todos registrados com o expediente de aceite no mês de março de 2020. 